\title{
Gender Gaps in Elementary Education in India in the post Right to Education Act Period: Implications for Policy
}

Nurzamal Hoque ${ }^{+*}$ and Ratul Mahanta*

\section{Abstract}

While the gender gaps in elementary education in India have almost been eliminated, we obtain somewhat different picture when adjusting the gaps to the appropriate school-age children (6-14 years) and the number of the child population. We calculate gender gaps in enrolment, transition rate (from primary to upper primary level), achievement in the examination, and test scores in different subjects in the post Right to Education Act period and obtain that girls are ahead of the boys in almost all aspects. The age-adjusted gender gap in enrolment has improved, implying that over time girls are more likely to enrol in schools within the appropriate school-age. Also, fewer girls are expected to remain out of schools compared to boys within the appropriate school-age. Perhaps, this progress in enrolment has resulted in better performances of girls in transition rate, achievement in examinations and test scores in individual subjects. The rising girls' performance on different indicators of elementary education indicates the potential impacts of female share on future labour market.

Keywords: Enrolment Ratio; Transition Rate; Labour Market; Human Rights; Gender Parity Index; India

\footnotetext{
${ }^{+}$Department of Economics, Pragjyotish College, Guwahati, Assam, India, 781009

* Corresponding Author, Email: nuramalhoque06@gmail.com

¥ Department of Economics, Gauhati University, Guwahati, Assam, India, 781014, Email: rmeco@gauhati.ac.in (C)2020 Hoque \& Mahanta. This is an Open Access article distributed under the terms of the Creative Commons Attribution License (http://creativecommons.org/licenses/by/2.0), which permits unrestricted use, distribution, and reproduction in any medium, provided the original work is properly cited.
} 


\section{Introduction}

Since the inception of the Universal Declaration of Human Rights in 1948, reduction in the gender gap, especially in elementary education, has remained a top priority in world education policies. The third Millennium Development Goals (MDGs) 2000 aimed at achieving gender equality in education by the year 2015. Likewise, the Sustainable Development Goals (SDGs) set in 2015 (Goals 4 and 5) have explicitly targeted to ensure gender equality in education (UNESCO, 2016b). Like many other countries, India has also been striving to reduce the persistent gender gaps in early school grades such as elementary education. Accordingly, achieving gender equality in primary or elementary education has remained one of the key focuses of many education policies and programs. The National Education Policy (NEP) 1968, 1986, and 2016; District Primary Education Program (DPEP), 1994; the Sarva Shiksha Abhiyan (SSA) Mission, 2001; or the Right to Education (RTE) Act, 2009 are some of the major ones.

The recently announced NEP 2020 (GOI, 2020) also pays adequate attention to bridging the persistent gender gaps in education. The NEP 2020 proposes to constitute a 'Gender-Inclusion Fund' to provide equitable quality education for all girls as well as transgender students. In essence, this policy aims to eliminate disparity in access to education for children from any gender and socio-economically disadvantaged group. For this, the policy plans to provide adequate and safe infrastructure, including clean drinking water, working toilets, electricity, computing devices, internet, libraries, clean and attractive spaces, and sports and recreational resources to all schools to ensure that teachers and students from all genders and with disabilities, receive an inclusive, effective, and safe learning environment.

While there are many root causes of the gender gap in education such as family background (Buchmann and DiPrete, 2006), socio-economic factors (Varughese and Bairagya, 2020), teacherstudent relationship (Hajovsky et al., 2017), educational access and opportunities (Lacour and Tissington, 2011; Tesema and Braeken, 2018), culture and religion (Cooray and Potrafke, 2011), other things remaining same, the gender gap in the early school grades tends to explain much of the gender differences in secondary or higher education. The reduction in the gender gap in education is crucial for changing the permanent component of gender inequality in the labour market, that is, abilities or productive capacities of workers (Arabage and Souza, 2019).

The conventional measures of the gender gap in education like gender parity index (GPI) or enrolment ratio provide a crude measure of gender differences as they do not take into account the age structure of school children and the share of the child population. The enrolment ratio adjusted for the school-age and the share of child population may be more effective in explaining the potential gender gap in enrolment. This is because a country or a state that has gender inequality in the child population of a specific age group may typically experience gender inequality in enrolment within the age group. We present here an analysis that explains age and child populationadjusted gender gap in elementary education across states and union territories (UTs) in India in the post Right to Education (RTE) Act, 2009 period. $^{1}$

While the conventional measures show a declining GPI in India, we obtain somewhat different results when adjusting it to appropriate school-age (6-14 years) children and the number of child population (6-14 years). Our analysis is similar in spirit to that of the observation made by Bandyopadhyay and Subrahmanian (2008), who examine the trend and pattern of gender inequality in education in India. . Bandyopadhyay and Subrahmanian (2008) found that although the proportionate share of girls' enrolment has increased rapidly during

\footnotetext{
${ }^{1}$ The RTE Act, 2009 specifies the right of all children to free and compulsory education irrespective of gender, caste, place of residence, and social group (The Gazette of India, 2009).
} 
1990-2005, substantial gender gap still exists with persistently high dropout rates of girls. We extend the calculation to the age and child population-adjusted enrolment and witness that girls are outperforming boys in both cases, with a few exceptions. Perhaps, girls' advantage in enrolment has led to the declining or reverse gender ratio in transition rate, achievements in examinations, and test scores in individual subjects over time. Our findings, that is, the overall improvement of girls in elementary education can provide not only useful complementary information to the existing literature on gender gaps in elementary education, but also has significant implications in reducing gender inequality in secondary or higher education and thus gender inequality in the future labour market.

The rest of the study is structured as follows. The next section provides an overview of gender gaps in the world as well as India, followed by a brief description of data used in the study. The method of calculating the gender gap in each dimension and results are discussed in the subsequent section. The concluding remarks are given in the final section.

\section{Overview of Gender Inequality}

Usually, the gender gap is defined as the state of unequal ease of access to resources and opportunities or basic social services by men and women. Gender inequality acknowledges that gender affects individuals' living experiences that arise from the differences in biology, psychology and cultural norms. Worldwide, there are significant differences in the types of inequality faced by women. In many countries, women do not have equal legal rights as men. A recent World Bank's report in 2019 on Women Business and the Law reveals that only six countries (Belgium, Denmark, France, Latvia, Luxembourg and Sweden) give women equal legal rights as men (World Bank, 2019).

The size of the gender gap would be more apparent if we go through a few examples where women share the unequal burden. Globally, a substantial number of women are still bearing the burden of teenage pregnancy (around 12 million girls are married off before they reach 18 years) (UNICEF, 2020). In terms of illiteracy, women makeup world's more than two-thirds of the illiterate adults, showing the extent of gender inequality in access to education opportunities (World's Women Report, 2015). Women also share a higher burden of family work (UN Women, 2015; Rubiano-Matulevich and Viollaz, 2019). According to the United Nation's 2012 report on MGDs, over 70 per cent of the burden of collecting water for households in sub-Saharan Africa falls on women and girls (United Nations, 2012).

Several efforts have been made to measure the extent of gender inequality across countries. As a more recent effort, the Global Gender Gap Index (GGGI) published by the World Economic Forum (WEF) since 2006 include four key areas namely health, education, economy and politics to gauge the state of gender equality (WEF, 2006). India's position in GGGI is not satisfactory. GGGI value in India has improved marginally from 0.601 in 2006 (ranked 98 $8^{\text {th }}$ out of 115 countries) to 0.668 in 2020 (ranked $112^{\text {th }}$ out of 153 countries), signifying the persistent higher levels of gender inequalities within the country (WEF, 2020).

Overwhelmingly, India has some higher levels of gender discrimination at birth, more commonly preferences for boys (Clark, 2000; Dahl and Moretti, 2008; Echavarri and Ezcurra, 2011; Kugler and Kumar, 2017; Jayachandran and Pande, 2017) that lead to unequal gender ratio across all age groups. The postnatal discrimination against girls leading to excess women mortality is a cause of skewed sex ratio in India (Guilmoto et al., 2018). The Ministry of Statistics and Program Implementation, Government of India (GOI) 2018 reports that the country has been experiencing a declining gender ratio among the child population in the last few years. For the age group $6-10$ years, the gender ratio has declined from 0.914 in 2011-12 to 0.905 in $2016-17$, whereas the gender ratios were 0.915 and 0.861 , respectively, for the age group 11-13 years. For the age group 14-15 years, the gender ratio has declined from 0.901 to 0.885 during the same period. The declining gender ratio is also observed for all age groups. 
As per 2011 Census, the overall gender ratio in India was 0.943 (0.949 in rural and 0.929 in urban areas). According to a recent estimate of GOI, the gender ratio in 2020 has declined to 0.924 .

However, perhaps not too surprisingly, the inequality or the declining gender ratio among the child population has led to the gender differences in enrolment in elementary education. We, therefore, adjust enrolment rates in elementary education by the number of the child population and the appropriate schoolage to estimate the potential gender difference in enrolment. While doing this, we get some ideas about how the gender differences in child population can lead to the gender differences in enrolment rates in elementary education in India. The following section discusses about the data sources and methods.

\section{Data Sources and Methods}

We consider all states and UTs to calculate the gender gap in various dimensions of elementary education in India during 2012-17. However, due to constraints relating to data, some states or UTs, or both have been excluded from the calculation. We calculate gender gaps in four dimensions: enrolment rate (actual and adjusted for age and child population), transition rate, achievement in examination (pass percentage), and test scores in individual subjects. Data on enrolment, transition rate and achievement in examinations are taken from State Report Cards (SRC) of District Information System for Education (DISE), various issues, managed and published by National University of Educational Planning and Administration (NUEPA), New Delhi, Ministry of Human Resource Development (MHRD), GOI; data on test scores in individual subjects are taken from National Achievement Survey, MHRD, GOI, various rounds; and child population data are taken from population projection by MHRD, GOI.

The study integrates both education and demographic variables in analysing gender

\footnotetext{
${ }^{2}$ Under-aged students are those who are younger than the official school-age range for the educational programme they are enrolled in, whereas over-aged students are
}

differences in various dimensions of elementary education. We use simple statistical tools for calculating gender ratios and adjusting them to age and child population. For each dimension, the details of the calculation process, the results and discussions associated with the calculation are summarised in the following sub-sections.

\section{Analysis and Discussion}

\section{Gender Gap in Enrolment}

Usually, the gender gap in enrolment, that is, Gender Parity Index (GPI) is measured by the ratio of the number of girls enrolled per 100 boys enrolled. We call it an actual gender gap or actual GPI. This actual GPI, however, sometimes may mislead because of at least two reasons. First, if a state or UT has a child sex ratio less than 1 , there may be a chance of getting actual GPI value less than 1 even if all girls are enrolled in schools. Second, actual GPI value includes both under-aged and over-aged enrolment, and hence it may fail to reflect the potential gender gap within the specific school-age population. ${ }^{2}$

Since actual GPI provides a crude measure of the gender gap in enrolment, we adjust it by appropriate school-age and the number of the child population. The age-adjusted GPI is calculated by subtracting both under-aged and over-aged students from total enrolment. Thus, we get a ratio of the number of girls enrolled per 100 boys enrolled within the age group of 6-14 years. Figure1 depicts both actual and ageadjusted GPI in 2011-12 and 2016-17. We see that with a few exceptions, age-adjusted GPI is much higher across states and UTs. The gap is highest in Meghalaya (0.720), followed by Haryana (0.796) and Punjab (0.809). In short, the actual GPI understates the gender gap by around 0.06 percentage point than the age-adjusted GPI. The lower age-adjusted GPI in Meghalaya is not surprising. Although Meghalaya is a matrilineal society, the overall enrolment in 2011-12 was accompanied with higher girls' share of under-aged and over-aged enrolment (73.54 per cent) than the boys (61.78 per cent).

those who are older than the official school-age range for the educational programme they are enrolled in. 
The reverse was the case in 2016-17, where boys share of under-aged and over-aged enrolment (79.65 per cent) overtook the girls' share (74.33 per cent).

In 2016-17, the age-adjusted (0.949) GPI outweigh the actual (0.926) GPI. The greatest improvement in age-adjusted GPI is observed in Meghalaya (1.279) followed by Mizoram (1.057) and Nagaland (1.009). In the same vein, Arunachal Pradesh, Assam and Bihar have achieved age-adjusted gender equality in enrolment. The age-adjusted GPI in 2016-17 has improved, indicating that over time girls are more likely to enrol in schools within the appropriate age (6-14 years). However, in 201617, Andhra Pradesh (0.931), Daman \& Diu (0.896) and Gujarat (0.878) have experienced higher age-adjusted gender gap than in 2011-12, where the values were $0.946,0.912$ and 0.922 respectively.

Figure 1: Gender Gap in Enrollment, 2011-12 and 2016-17

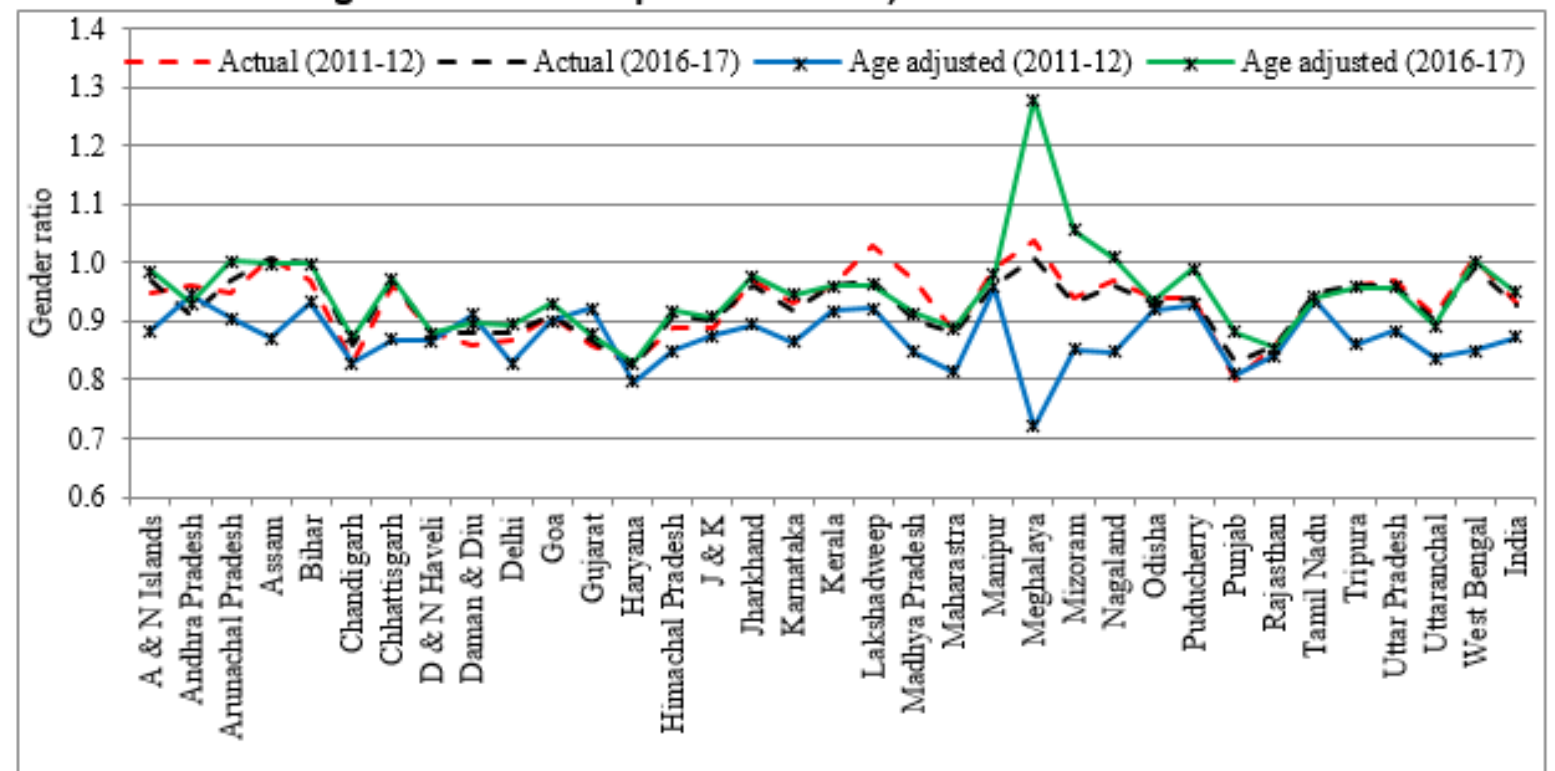

Source: Authors' calculation based on State Report Cards (SRC) of District Information System for Education (DISE) and population projection by Ministry of Human Resource Development (MHRD), Government of India (GOI)

Although the age-adjusted gender gap in enrolment has decreased over time, but the variation across states and UTs has increased at an annual rate of 9.35 per cent during 2011-12 and 2016-17. That is, girls' performances are comparatively lagging behind in some states and UTs that need more strategic intervention. The increasing variation across states and UTs is also evident from the ratio of top five to bottom five performing states and UTs (an increase from 1.185 to 1.240 during the same period).

We then adjust the age-adjusted GPI to the number of child population. ${ }^{3}$ The age and child

\footnotetext{
${ }^{3}$ Population estimation made by MHRD is available under six broad categories of age groups: 6-10, 11-13, 14-15, 16$17,18-22$, and $18-23$ years. To get the number of children within the age group of 6-14 years, we calculate the
}

population-adjusted GPI gives us the ratio of relative share of girls to boys' enrolment within the age group 6-14 years. We see that within the age group 6-14 years, the share of girls' enrolment has improved than the boys. In 201617 , most of the states and UTs have experienced age, and child population-adjusted GPI value higher than 1 (see Figure 2). That is, the gender gap has reversed in terms of age and child population-adjusted GPI. The age and child population-adjusted GPI values in both 2011-12 and 2016-17 are higher than their actual and age-adjusted GPI values.

average number of children in a single year between age group '6-15' and then this average is added to the number of 6-10 and $11-13$ years age group. 
Similar to age-adjusted GPI, the variability of age and child population-adjusted GPI has also increased across states and UTs. This time, the variability across states and UTs have increased more rapidly (15.25 per cent annually) than in the case of age-adjusted GPI (9.35 per cent annually).

Figure 2: Gender Gap in Enrollment, Age and Child Population Adjusted

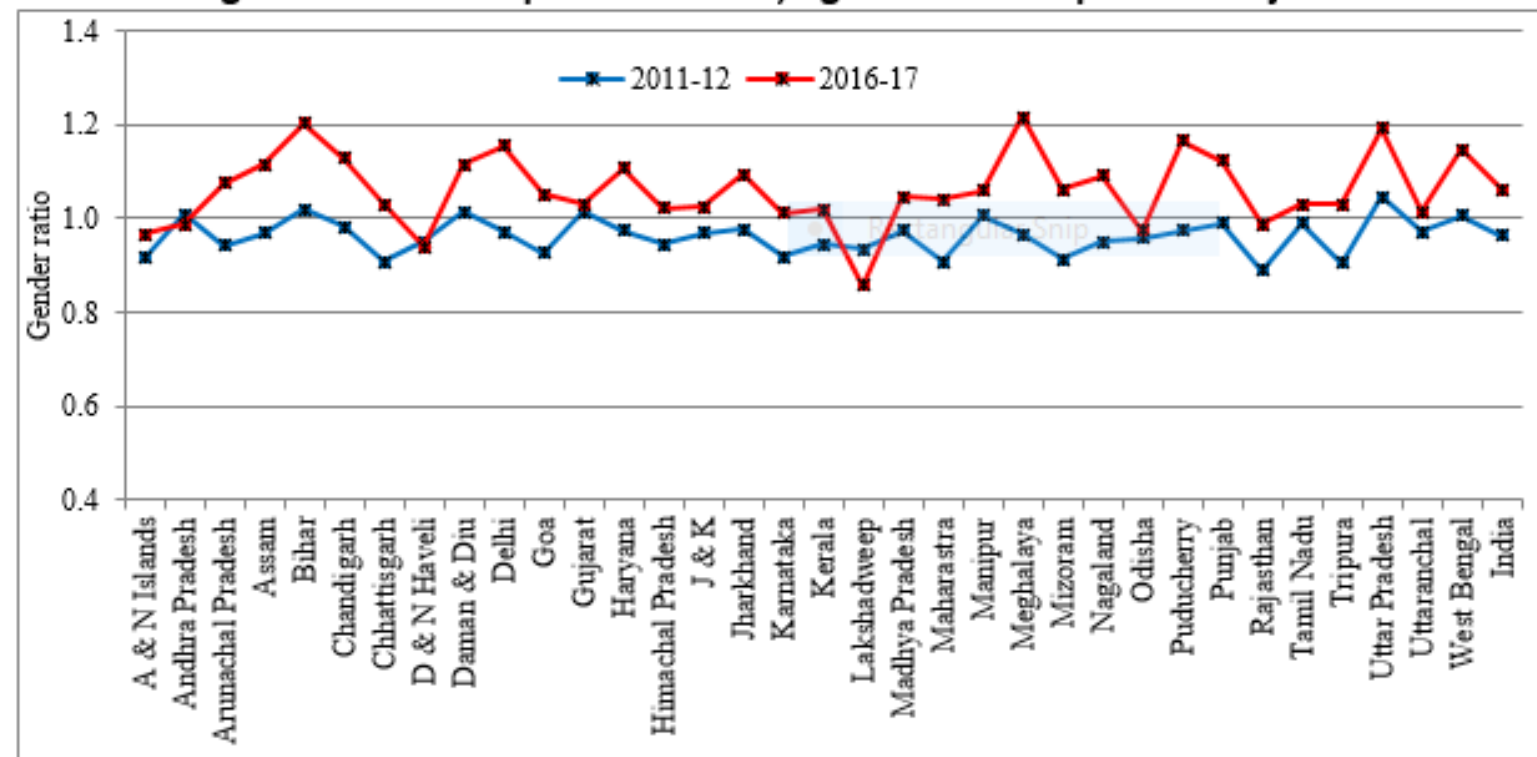

Source: Authors' calculation based on SRC of DISE and population projection by MHRD, GOI

\section{Gender Gap in the Transition Rate}

While the position of girls in age and child population-adjusted enrolment has been most impressive, there has also been a considerable improvement of girls in terms of transition rate from primary to upper primary level. Due to the lack of data, we calculate the gender ratio of transition rate only for all enrolled students irrespective of their ages. The transition rates for boys and girls are separately available for 201516 and 2016-17 (see Figure 3).

In both periods, transition rates of the girls are higher in majority of the states and UTs than that of the boys. Some states are continuously experiencing higher gender gap in transition rates. At the other end in Assam, Delhi, Uttar Pradesh, West Bengal, Jharkhand transition of the girls is far better than the boys. The average transition rate and variation across states and UTs in terms of transition rate in these two periods have remained almost unchanged. Girls are continuously outperforming boys in transition rate, suggesting fewer girls are likely to leave schools during the primary education cycle than boys. 
Figure 3: Gender Gap in Transition Rate from Primary to Upper Primary, 2015-16 and 2016-17

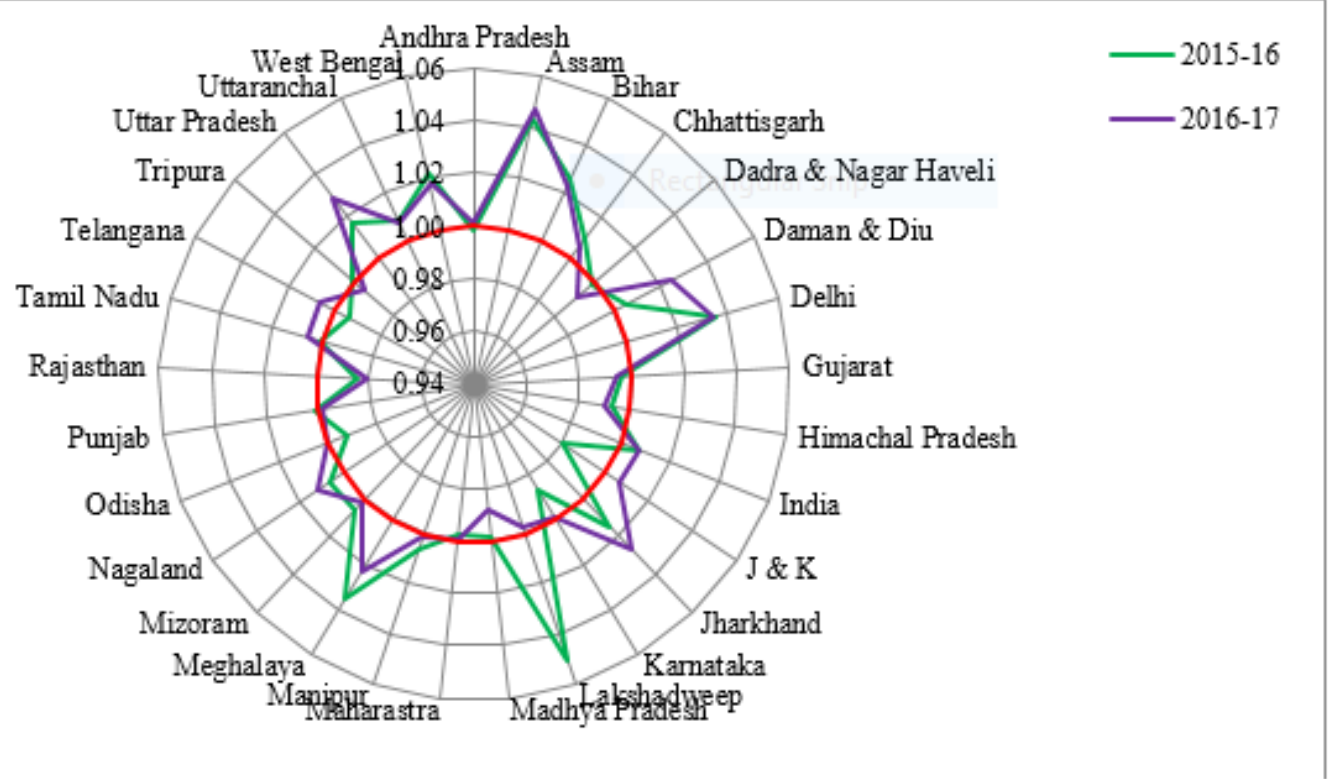

Note: Red line shows gender equality.

Source: Authors' calculation based on SRC of DISE and population projection by MHRD, GOI

\section{Gender Gap in Achievement in the Examination}

While the gender gaps in enrolment and transition rate show the comparative analysis of boys and girls in attaining schools and promotion rate from a lower level to a higher level, an analysis is also needed to demonstrate the relative learning achievements of boys and girls. Based on available data, we calculate gender differences in achievement in examination (without adjusting for age and child population) as a proxy for learning achievement for Class $V$ and Class VIII students in 2013-14 and 2015-16 (please refer to Figure 4 and Figure 5). The average pass percentages of boys and girls in all states and UTs are nearly 100 (ranges between 98.2 and 98.8 per cent) in both Class $V$ and Class VIII examinations (data not shown in the figure).

Figure 4: Gender Gap in Class V Examination (passed with $\geq 60$ per cent), 2013-14 and 2015-16

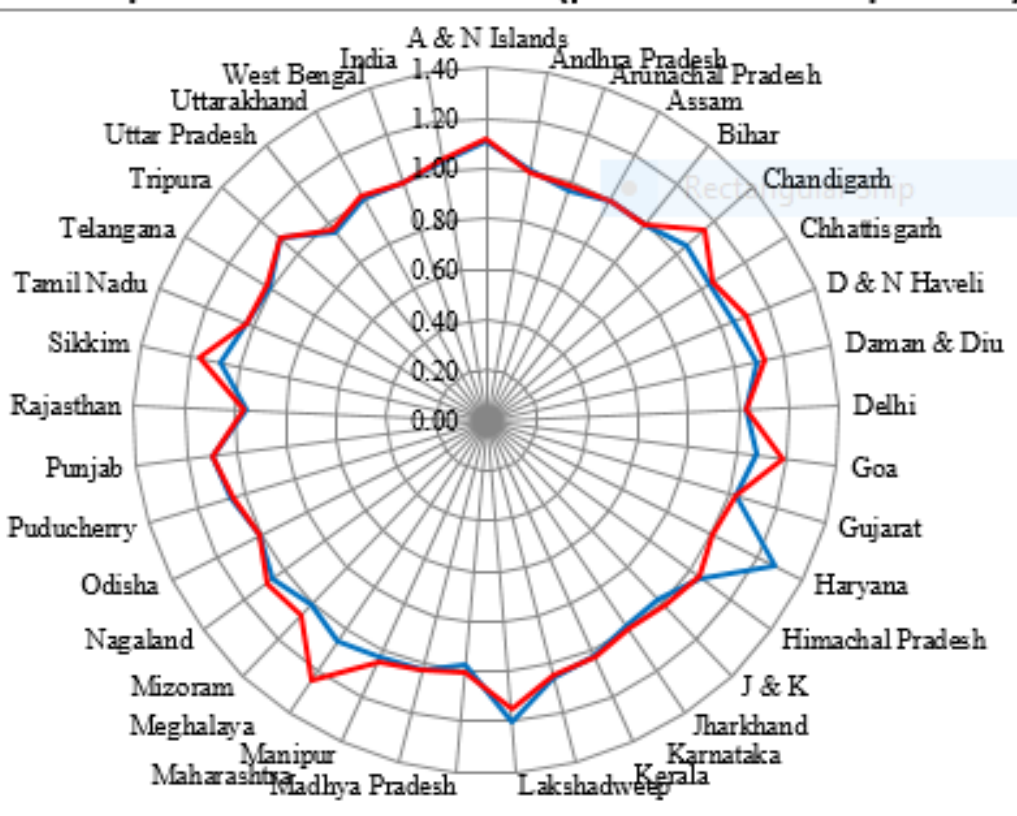

Source: Authors' calculation based on SRC of DISE 
There has been a mild increase in the pass percentage of boys and girls during 2013-14 and 2015-16. These data indicate achievement of the 'no-detention' policy (NDP) of the RTE Act, 2009. ${ }^{4}$ However, the NDP was changed in 2016, where the RTE Act permits schools to detain children in Class V and Class VIII they fail an annual exam twice. Since the pass percentages for boys and girls are almost equal, the gender ratios of pass percentages are closely equal to 1 .
Girls, on an average, are doing better in examinations than boys if we consider the pass percentages with 60 per cent or more marks. Accordingly, gender ratios of pass percentages (60 per cent or more) are higher than 1.In Class VIII examination, the highest gender ratio is observed in Lakshadweep (1.588) in 2013-14, followed by Goa (1.468) and Chandigarh (1.382) in 2015-16.

Figure 5: Gender Gap in Class VIII Examination (passed with $\geq 60$ per cent), 2013-14 and 2015-16

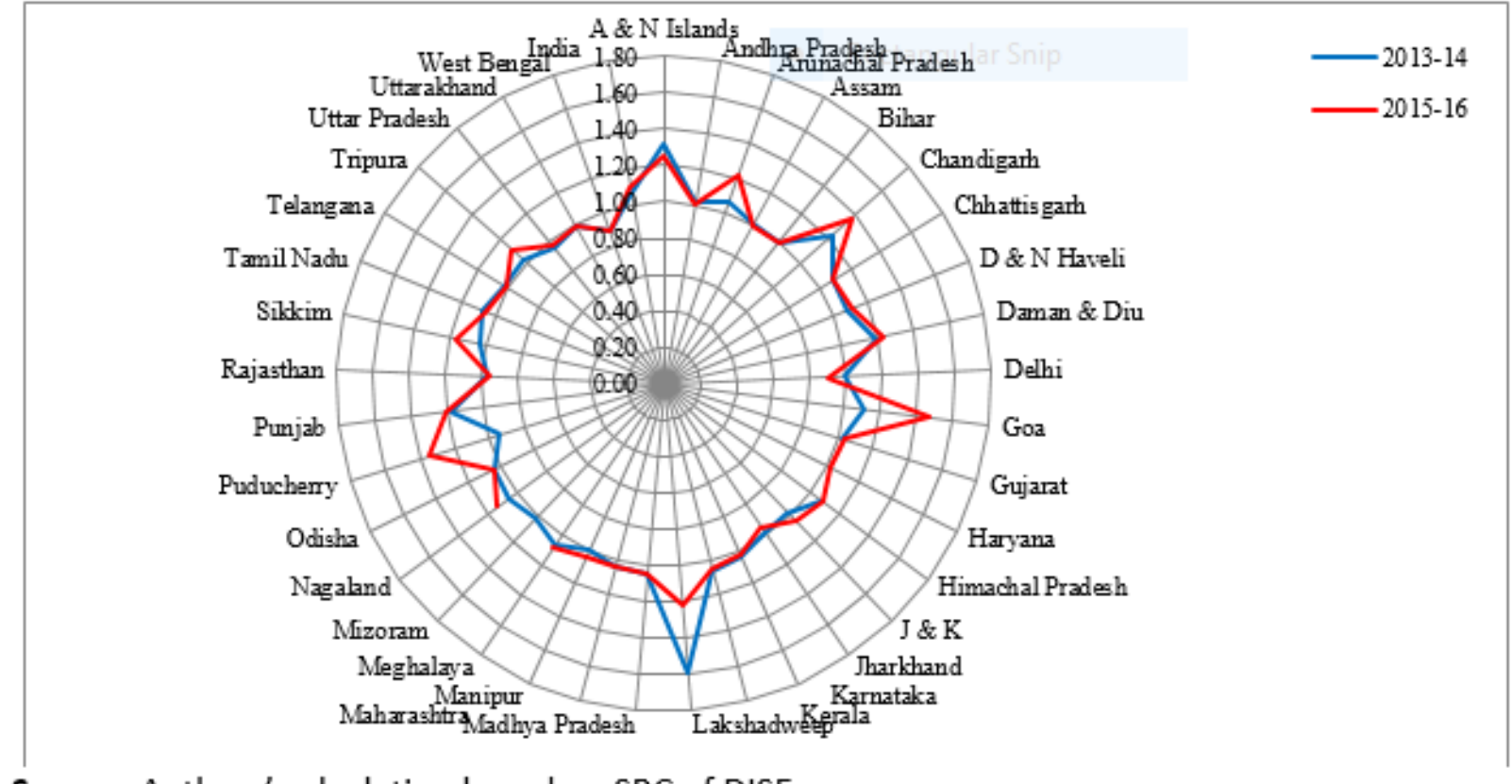

Source: Authors' calculation based on SRC of DISE

Surprisingly, the percentages of boys and girls passed with 60 per cent or more marks have declined during the study period, albeit at a low rate. This declining rate, however, is slightly higher for boys leading to an increase in gender ratio over time. ${ }^{5}$ The average gender ratio (passed with 60 per cent or more) for class $V$ has increased from 1.042 in 2013-14 to 1.054 in 2015-16, whereas the same figures are 1.064 and 1.093 respectively for Class VIII. One of the reasons for this decline may be because of the declining quality of government schools in recent years. ${ }^{6}$ Lakshadweep, which has no private schools, is an exception to this, that is,

\footnotetext{
${ }^{4}$ The 'no-detention' policy of the RTE Act deems that no student should be failed from school until they complete their elementary education (The Gazette of India, 2009).
}

government schools in Lakshadweep are doing better.

\section{Gender Gap in Test Scores}

Even if girls' performance in overall achievement in the examination is quite impressive; we made an attempt to examine the relative performances of boys and girls in Class VIII test scores of individual subjects namely Reading Comprehension, Language, Mathematics, Science and Social Science in 2014 and 2017. These test scores, however, are restricted to the students of government and government-aided elementary schools. Table1 summaries the

\footnotetext{
${ }^{5}$ Factors affecting unequal learning achievements of boys and girls are discussed by Lai (2010), Voyer and Voyer (2014), UNESCO (2016a).

${ }^{6}$ Scholars like Kundu (2019) observe the declining quality of government schools in India in recent years.
} 
gender ratios of Class VIII test scores. We see Science disappeared in 2017. In contrast to the that, on average, girls' are performing better increasing variability of the age and child than boys. Girls are outperforming boys in population-adjusted GPI, the variation across Reading Comprehension, Language and Social states and UTs in terms of test scores came down Science in both 2014 and 2017, whereas the in 2017 than in 2014 (see standard deviation gender gaps in test scores in Mathematics and values).

\begin{tabular}{|c|c|c|c|c|c|c|c|c|}
\hline & \multirow{2}{*}{$\begin{array}{c}\text { Reading } \\
\text { Comprehension } \\
2014\end{array}$} & \multirow{2}{*}{$\begin{array}{c}\text { Language } \\
2017\end{array}$} & \multicolumn{2}{|c|}{ Mathematics } & \multicolumn{2}{|c|}{ Science } & \multicolumn{2}{|c|}{$\begin{array}{l}\text { Social } \\
\text { Science }\end{array}$} \\
\hline & & & 2014 & 2017 & 2014 & 2017 & 2014 & 2017 \\
\hline A \& N Islands & 1.029 & 1.061 & 1.000 & 1.030 & 1.015 & 1.057 & 1.028 & 1.088 \\
\hline Andhra Pradesh & 1.017 & 1.017 & 0.987 & 1.000 & 1.008 & 1.021 & 0.987 & 1.000 \\
\hline Arunachal Pradesh & 0.996 & 0.978 & 1.004 & 1.000 & 0.980 & 1.000 & 1.004 & 1.029 \\
\hline Assam & - & 1.000 & - & 1.000 & - & 1.000 & - & 0.980 \\
\hline Bihar & 0.960 & 0.966 & 0.985 & 0.978 & 0.988 & 0.978 & 1.000 & 1.000 \\
\hline Chandigarh & 1.027 & 1.033 & 0.992 & 1.044 & 1.000 & 1.020 & 1.008 & 1.038 \\
\hline Chhattisgarh & 0.984 & 1.018 & 1.008 & 1.028 & 1.012 & 1.023 & 1.000 & 1.000 \\
\hline D \& N Haveli & 1.004 & 1.069 & 1.016 & 1.045 & 0.989 & 1.063 & 0.996 & 1.078 \\
\hline Daman \& Diu & 1.045 & 1.078 & 1.016 & 1.000 & 0.993 & 1.030 & 1.000 & 1.091 \\
\hline Delhi & 1.058 & 1.057 & 0.996 & 1.000 & 1.017 & 1.000 & 1.043 & 1.059 \\
\hline Goa & 1.040 & 1.052 & 1.008 & 0.971 & 1.027 & 0.974 & 1.036 & 1.083 \\
\hline Gujarat & 1.025 & 1.065 & 0.991 & 1.043 & 0.992 & 1.020 & 1.017 & 1.038 \\
\hline Haryana & 1.020 & 1.036 & 0.984 & 1.056 & 1.000 & 1.000 & 1.004 & 1.049 \\
\hline Himachal Pradesh & 0.988 & 1.017 & 0.953 & 0.972 & 0.972 & 0.977 & 0.972 & 1.000 \\
\hline J \& K & 0.967 & 0.955 & 0.959 & 0.974 & 0.980 & 1.000 & 0.988 & 0.971 \\
\hline Jharkhand & 1.000 & 1.017 & 1.020 & 1.020 & 1.032 & 1.000 & 1.030 & 1.000 \\
\hline Karnataka & 1.021 & 1.032 & 1.008 & 1.040 & 0.992 & 1.019 & 1.004 & 1.020 \\
\hline Kerala & 1.095 & 1.082 & 1.017 & 1.000 & 1.023 & 1.000 & 1.052 & 1.000 \\
\hline Lakshadweep & - & 1.085 & - & 0.970 & - & 0.970 & 0.000 & 1.034 \\
\hline Madhya Pradesh & 1.000 & 1.037 & 0.989 & 1.026 & 0.996 & 1.023 & 0.985 & 1.000 \\
\hline Maharashtra & 1.023 & 1.049 & 0.992 & 1.025 & 0.976 & 0.976 & 0.996 & 1.000 \\
\hline Manipur & 1.000 & 1.000 & 1.004 & 1.000 & 1.004 & 1.000 & 0.992 & 1.024 \\
\hline Meghalaya & 1.000 & 1.021 & 1.000 & 1.029 & 1.009 & 1.029 & 1.027 & 1.027 \\
\hline Mizoram & 1.008 & 1.070 & 1.029 & 1.086 & 0.996 & 1.000 & 1.004 & 1.063 \\
\hline Nagaland & 0.988 & 1.000 & 1.004 & 1.030 & 0.988 & 1.029 & 0.988 & 1.000 \\
\hline Odisha & 0.996 & 1.019 & 0.976 & 1.000 & 0.969 & 0.977 & 0.979 & 1.000 \\
\hline Puducherry & 1.048 & 1.091 & 1.013 & 1.067 & 1.026 & 1.000 & 1.037 & 1.036 \\
\hline Punjab & 1.043 & 1.077 & 1.000 & 1.032 & 1.004 & 1.000 & 1.008 & 1.029 \\
\hline Rajasthan & 1.008 & 1.000 & 1.008 & 1.000 & 1.000 & 1.000 & 1.016 & 1.000 \\
\hline Sikkim & 0.992 & 1.040 & 0.979 & 1.000 & 0.996 & 1.027 & 0.988 & 1.000 \\
\hline Tamil Nadu & 1.038 & 1.073 & 1.022 & 1.029 & 1.013 & 1.000 & 1.022 & 1.030 \\
\hline Telangana & - & 1.019 & - & 1.000 & - & 0.974 & - & 1.000 \\
\hline Tripura & 1.013 & 1.000 & 1.023 & 0.974 & 0.981 & 0.976 & 1.004 & 1.000 \\
\hline Uttar Pradesh & 1.008 & 1.000 & 1.004 & 1.025 & 1.004 & 1.000 & 0.967 & 1.024 \\
\hline Uttarakhand & 0.992 & 0.983 & 0.992 & 0.976 & 0.984 & 0.958 & 0.992 & 0.939 \\
\hline West Bengal & 0.981 & 0.964 & 0.984 & 0.950 & 0.962 & 0.952 & 0.976 & 0.974 \\
\hline India & 1.012 & 1.018 & 0.996 & 1.000 & 0.996 & 1.000 & 1.004 & 1.023 \\
\hline SD & 0.285 & 0.037 & 0.280 & 0.031 & 0.280 & 0.025 & 0.282 & 0.034 \\
\hline
\end{tabular}

Source: Authors' calculation based on National Achievement Survey, various rounds

It is evident that girls are outperforming boys in transition rates, examination results, and test scores in individual subjects in most of the states and UTs. Our results are similar to the findings of many previous studies that observe the reverse gender gap in academic or learning 
achievements from favouring boys to favouring girls (Pomerantz et al., 2002; Houtte, 2004; Mickelson and Greene, 2006; Lai, 2010; Goldin et al., 2006; Hajovsky et al., 2017). While girls' dominances in schools are common findings in education research which extend to most of the subjects such as Mathematics, Science, and Language (Voyer and Voyer, 2014), our results also hold true for Social Science or Reading Comprehension. If this trend continues in elementary education, it can help in reducing the gender gap in higher education and thereby reducing persistent gender gaps in society as a whole. However, still, there is no universal consensus regarding how to quantify gender differences and their moderator variables (Voyer and Voyer, 2014).

\section{Conclusion}

This study made an attempt to find out potential gender differences in various aspects of elementary education in India. The findings demonstrate that the ratios of boys to girls in some indicators of elementary education have reversed in the post-RTE Act period. Typically, the reverse gender differences in transition rates, achievements in examinations, and test score in individual subjects of elementary education have important implications for better performance of girls in secondary and higher education. The rising girls' advantages in different indicators of elementary education will also have important implications in explaining the potential impact of gender on labour market. Further analysis that links the relation between gender gap in elementary education and labour force participation rate would be more fruitful.

\section{References}

Arabage, A. C. and Souza, A. P. (2019). Wage Dynamics and Inequality in the Brazilian formal Labor Market. EconomiA, 20, 153-90. https://doi.org/10.1016/j.econ.2019.10.001

Bandyopadhyay, M. and Subrahmanian, R. (2008). Gender Equity in Education: A Review of Trends and Factors. Consortium for Research on Educational Access, Transitions and Equity.

Research Monograph No 18. http://sro.sussex.ac.uk/id/eprint/1866
Buchmann, C. and DiPrete, Thomas A. (2006). The Growing Female Advantage in College Completion: The Role of Family Background and Academic Achievement. American Sociological Review, 71, 515-41.

https://doi.org/10.1177\%2F0003122406071004 01

Clark, S. (2000). Son Preference and Sex Composition of Children: Evidence from India. Demography, 37(1), 95-108. DOI:

$10.2307 / 2648099$

Cooray, A. and Potrafke, N. (2011). Gender Inequality in Education: Political Institutions or Culture and Religion? European Journal of Political Economy, 27(2), 268-80.

DOI: 10.1016/j.ejpoleco.2010.08.004

Dahl, Gordon B. and Moretti, E. (2008). The Demand for Sons. The Review of Economic Studies, 75. 1085-1120.

https://doi.org/10.1111/j.1467-

937X.2008.00514.x

Echavarri, R. and Ezcurra, R. (2011). Education and Gender Bias in the Sex Ratio at Birth: Evidence From India. Demography, 47(1), 249268. DOI: $10.1353 /$ dem.0.0089

GOI (2018). Women and Men in India. A statistical compilation of Gender related Indicators in India, Central Statistics Office Ministry of Statistics and Programme Implementation, GOI.

http://www.mospi.gov.in/sites/default/files/pu blication_reports/Women\%20and\%20Men\%20 \%20in\%20India\%202018.pdf

GOI (2020). National Education Policy 2020.

Ministry of Human Resource Development, GOI. https://www.mhrd.gov.in/sites/upload_files/m hrd/files/NEP_Final_English_0.pdf

Goldin, C., Lawrence F. Katz, and Kuziemko, I. (2006). The Homecoming of American College Women: The Reversal of the College Gender Gap. Journal of Economic Perspectives, 20(4), 133-56. DOI: 10.1257/jep.20.4.133

Guilmoto, C. Z., Saikia, N., Tamrakar, V., Bora, J. K. (2018). Excess under-5 female Mortality across India: A Spatial Analysis using 2011 Census data. The Lancet: Global Health, 6, 
https://doi.org/10.1016/s2214-109x(18)301840

Hajovsky, Daniel B., Benjamin A. Mason, Luke A. McCune (2017). Teacher-student relationship quality and academic achievement in elementary school: A longitudinal examination of gender differences, Journal of School Psychology, 63, 119-33.

DOI: 10.1016/j.jsp.2017.04.001

Houtte, Mieke V. (2004). Why Boys Achieve less at School than Girls: The Difference Between Boys' and Girls' Academic Culture. Educational Studies, 30(2), 159-73.

https://doi.org/10.1080/030556903200015980 4

Jayachandran, S. and Rohini Pande, R. (2017). Why Are Indian Children So Short? The Role of Birth Order and Son Preference. American Economic Review, 107(9), 2600-29. https://doi.org/10.1257/aer.20151282

Kugler, Adriana D. and Kumar, S. (2017). Preference for Boys, Family Size, and Educational Attainment in India. Demography, 54, 835-59. https://doi.org/10.1007/s13524017-0575-1

Kundu, P. (2019). Deteriorating Quality of Education in Schools: Are Teachers Responsible? Economic \& Political Weekly, 54(24), 34-41.

https://www.epw.in/journal/2019/24/specialarticles/deteriorating-quality-educationschools.html

Lacour, M., Tissington, L. D. (2011). The Effects of Poverty on Academic Achievement.

Educational Research and Review, 6(7), 522-27.

Lai, F. (2010). Are Boys Left Behind? The Evolution of the Gender Achievement Gap in Beijing's Middle Schools. Economics of Education Review, 29(3), 383-99.

https://doi.org/10.1016/j.econedurev.2009.07. 009

Mickelson, R. A., and Greene, A. D. (2006). Connecting Pieces of the Puzzle: Gender Differences in Black middle School Students' Achievement. Journal of Negro Education, 75, 34-48.
Pomerantz, E. M., Altermatt, E. R., and Saxon, J. L. (2002). Making the Grade but Feeling Distressed: Gender differences in Academic Performance and Internal Distress. Journal of Educational Psychology, 94, 396-404.

DOI: 10.1037/0022-0663.94.2.396

Rubiano-Matulevich E. C. and Viollaz, M. (2019). Gender Differences in Time Use Allocating Time between the Market and the Household. Policy Research Working Paper 8981. Available at https://ssrn.com/abstract=3437824, accessed on 10 September 2020

Tesema, M. T. and Braeken, J. (2018). Regional Inequalities and Gender Differences in Academic Achievement as a Function of Educational Opportunities: Evidence from Ethiopia. International Journal of Educational Development, 60, 51-9. https://doi.org/10.1016/j.ijedudev.2017.10.023

The Gazette of India (2009). The Right of Children to Free and Compulsory Education Act, 2009. New Delhi, Ministry of Law and Justice. https://www.mhrd.gov.in/sites/upload_files/m hrd/files/upload_document/rte.pdf

UN Women (2015). Progress of the world's women 2015-2016: Transforming Economies, Realizing Rights. United Nations Entity for Gender Equality and the Empowerment of Women. https://www.unwomen.org/en/digitallibrary/publications/2015/4/progress-of-theworlds-women-2015

UNESCO (2016a). Gender inequality in learning achievement in primary education. What can TERCE tell us? UNESCO and the Regional Office for Education in Latin America and the Caribbean.

https://unesdoc.unesco.org/images/0024/0024 43/244349e.pdf

UNESCO (2016b). Education 2030: Incheon Declaration and Framework for Action for the Implementation of Sustainable Development Goal 4: Ensure Inclusive and Equitable Quality Education and Promote Lifelong Learning Opportunities for All. ED-2016/WS/28. UNESCO, Paris.

http://uis.unesco.org/sites/default/files/docum 
ents/education-2030-incheon-framework-foraction-implementation-of-sdg4-2016-en_2.pdf

UNICEF (2020). Child Marriage around the World. https://www.unicef.org/stories/childmarriage-around-world

United Nations (2012). The Millennium Development Goals Report 2012. United Nations, New Work. https://doi.org/10.18356/32f1e244-en

Varughese, A. R. and Bairagya, I. (2020). Groupbased Educational Inequalities in India: Have Major Education Policy Interventions been Effective? International Journal of Educational Development, 73, 102-59. https://doi.org/10.1016/j.ijedudev.2020.10215 9

Voyer, D. and Voyer, Susan D. (2014). Gender Differences in Scholastic Achievement: A MetaAnalysis. Psychological Bulletin, 140(4), 11741204. https://doi.org/10.1037/a0036620

WEF (2006). The Global Gender Gap Report 2006, Geneva, Switzerland.

http://www3.weforum.org/docs/WEF_GenderG ap_Report_2006.pdf

WEF (2020). The Global Gender Gap Report 2006, Geneva, Switzerland.

http://www3.weforum.org/docs/WEF_GGGR_2 020.pdf
World Bank (2019). Women, Business and the Law 2019, A Decade of Reform. The World Bank, Washington DC.

http://hdl.handle.net/10986/31327

World's Women Report (2015). The World's Women 2015: Trends and Statistics. Department of Economic and Social Affairs, United Nations, New York. DOI: 10.18356/9789210573719

\section{Conflict of Interest}

The authors declare no conflict of interest

\section{Acknowledgements}

The first author acknowledges with gratitude the support of the Gauhati University for providing space and other facilities to conduct the PhD work from which the paper has been prepared. The first author also thanks to the Indian Council of Social Science Research (ICSSR) Government of India for providing fellowship for the entire PhD work. Both the authors would also like to thank the anonymous reviewers for their detailed comments that significantly helped to improve the manuscript.

\section{Author Contribution Statement}

N. Hoque and R. Mahanta conceptualised the research and methodology. N. Hoque conceived as well as designed the formal analysis and prepared the whole paper. 